San Jose State University

SJSU ScholarWorks

Master's Theses

Master's Theses and Graduate Research

1992

\title{
Role overlap between occupational therapists and recreational therapists in the field of mental health
}

\author{
Elaine Paulson Saghafian \\ San Jose State University
}

Follow this and additional works at: https://scholarworks.sjsu.edu/etd_theses

\section{Recommended Citation}

Saghafian, Elaine Paulson, "Role overlap between occupational therapists and recreational therapists in the field of mental health" (1992). Master's Theses. 359.

DOI: https://doi.org/10.31979/etd.9d58-fmcu

https://scholarworks.sjsu.edu/etd_theses/359

This Thesis is brought to you for free and open access by the Master's Theses and Graduate Research at SJSU ScholarWorks. It has been accepted for inclusion in Master's Theses by an authorized administrator of SJSU ScholarWorks. For more information, please contact scholarworks@sjsu.edu. 


\section{INFORMATION TO USERS}

This manuscript has been reproduced from the microfilm master. UMI films the text directly from the original or copy submitted. Thus, some thesis and dissertation copies are in typewriter face, while others may be from any type of computer printer.

The quality of this reproduction is dependent upon the quality of the copy submitted. Broken or indistinct print, colored or poor quality illustrations and photographs, print bleedthrough, substandard margins, and improper alignment can adversely affect reproduction.

In the unlikely event that the author did not send UMI a complete manuscript and there are missing pages, these will be noted. Also, if unauthorized copyright material had to be removed, a note will indicate the deletion.

Oversize materials (e.g., maps, drawings, charts) are reproduced by sectioning the original, beginning at the upper left-hand corner and continuing from left to right in equal sections with small overlaps. Each original is also photographed in one exposure and is included in reduced form at the back of the book.

Photographs included in the original manuscript have been reproduced xerographically in this copy. Higher quality $6 "$ x 9 " black and white photographic prints are available for any photographs or illustrations appearing in this copy for an additional charge. Contact UMI directly to order.

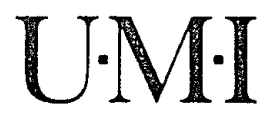



Order Number 1948720

Role overlap between occupational therapists and recreational therapists in the field of mental health

Saghafian, Elaine Paulson, M.S.

San Jose State University, 1992 

ROLE OVERLAP BETWEEN OCCUPATIONAL THERAPISTS AND RECREATIONAL THERAPISTS IN THE FIELD OF MENTAL HEALTH

\author{
A Thesis \\ Presented to \\ The Faculty of the Department of Occupational Therapy \\ San Jose State University \\ In Partial Fulfillment \\ of the Requirements for the Degree \\ Master of Science
}

By

Elaine Paulson Saghafian

May, 1992 
APPROVED FOR THE DEPARTMENT OF OCCUPATIONAL THERAPY
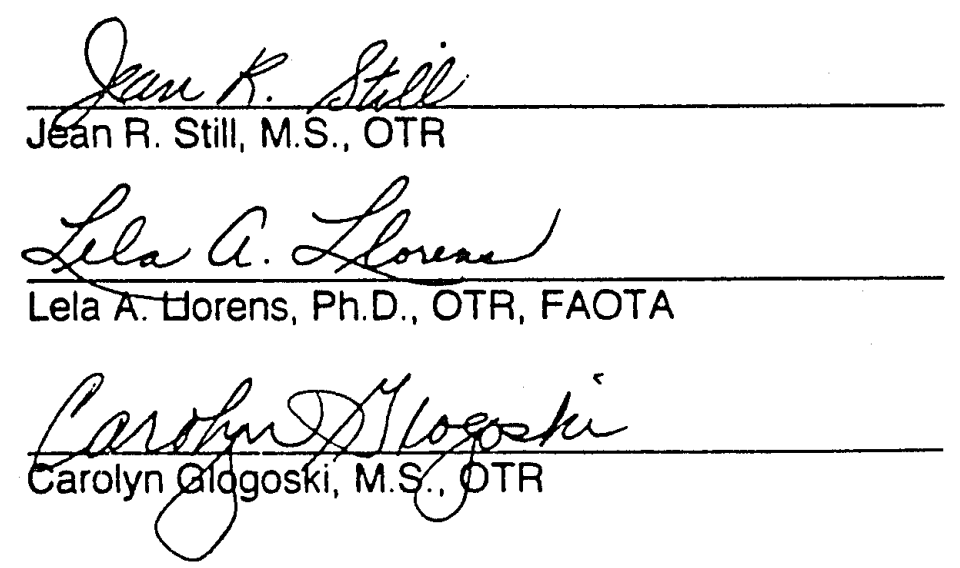

APPROVED FOR THE UNIVERSITY

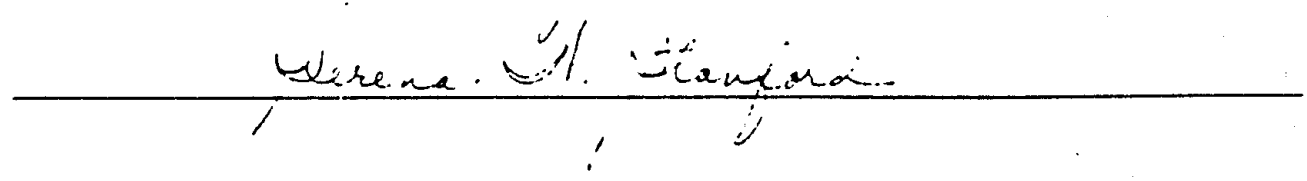




\section{ABSTRACT \\ ROLE OVERLAP BETWEEN OCCUPATIONAL THERAPISTS AND RECREATIONAL THERAPISTS IN THE FIELD OF MENTAL HEALTH \\ by Elaine Paulson Saghafian}

A descriptive study utilizing survey methodology was conducted to determine the extent of role overlap between occupational therapists and recreational therapists working in mental health settings. Seventy-eight occupational therapists and twenty-eight recreational therapists were included in the study. These two groups of respondents were compared according to frequency of modality use and ratings of goal importance in treatment planning.

Results indicated that there is extensive overlap between occupational and recreational therapists in their modalities and goals. Data from the goals section of the questionnaire were essentially inconclusive, as both groups indicated the majority of goals as "very important." The results of the study have implications for the future of occupational therapy in mental health, and recommendations are made for further research in this area. 


\section{ACKNOWLEDGEMENTS}

The author wishes to express sincere appreciation to her thesis advisor, Jean R. Still, M.S., OTR, for all of her suggestions and guidance throughout this research. Special thanks to my thesis readers, Lela Llorens, Ph.D., OTR, FAOTA, and Carolyn Glogoski-Williams, M.S., OTR, for their assistance in the completion of this thesis.

Appreciation is also extended to those occupational therapists and recreational therapists who participated in this study without whom this research would not have been possible.

Last, but not least, a most special thank you to my husband, David, for all his support, for tolerating my constant frustrations, and especially for doing all the cooking and cleaning during this time so that I could meet my deadlines. 
TABLE OF CONTENTS

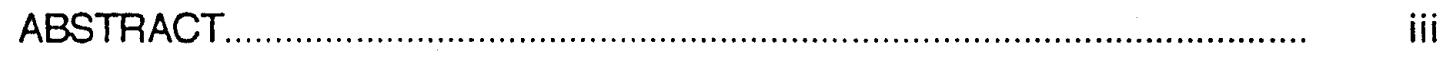

ACKNOWLEDGEMENTS..................................................................... iv

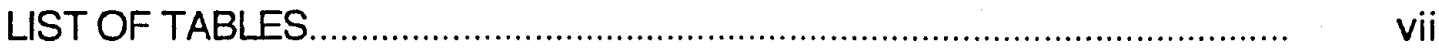

CHAPTER 1. INTRODUCTION .................................................................. 1

Purpose .................................................................................... 1

Statement of the Problem.................................................... 1

Objectives................................................................................... 2

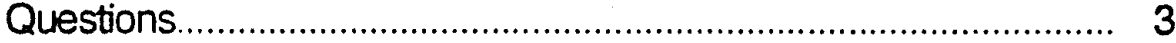

Definitions............................................................................... 3

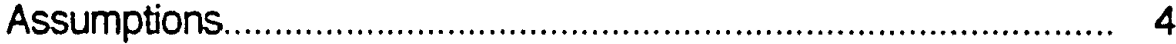

Limitations............................................................................... 4

Significance of the Study...................................................... 5

CHAPTER 2. REVIEW OF THE LITERATURE ........................................... 6

Background of Occupational Therapy.................................... 6

Roles of the Occupational Therapist...................................... 7

Background of Recreational Therapy..................................... 8

Roles of the Recreational Therapist......................................... 9

Effects of Role Overlap on Occupational Therapists................ 9

Summary................................................................................. 12

CHAPTER 3. METHODOLOGY AND RESULTS........................................... 14

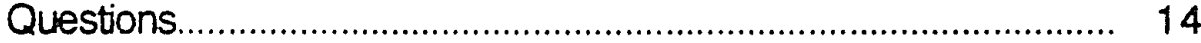

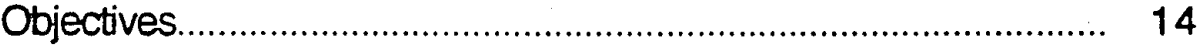

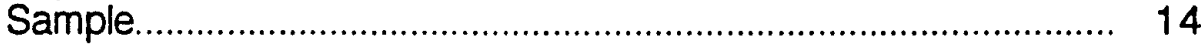

Data Collection................................................................ 15

Data Analysis Procedures..................................................... 16

Demographic Data............................................................... 16

Modality Use by Occupational Therapists.............................. 19

Goals Reported by Occupational Therapists.......................... 19

Modality Use by Recreational Therapists............................. 25

Goals Reported by Recreational Therapists......................... 25

Comparison of Modality Use................................................ 32

Comparison of Major Goals................................................. $\quad 38$

CHAPTER 4. DISCUSSION, IMPLICATIONS, AND

RECOMMENDATIONS.

Modality Use by Occupational Therapists.............................. 43 
Modality Use by Recreational Therapists................................ 44

Goal Importance for Occupational Therapists........................ 44

Goal Importance for Recreational Therapists......................... 45

Comparison of Modalities....................................................... 45

Comparison of Goal Importance............................................. 46

Conclusions.......................................................................... 47

Implications ........................................................................... 48

Recommendations................................................................... 49

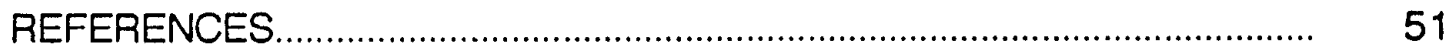

APPENDICES

A. Questionnaire .................................................................... 53

B. Cover Letter.................................................................. 58 


\section{LIST OF TABLES}

1. Type of Mental Health Setting in which Respondents Practice.

2. Modalities Used by Occupational Therapists without Recreational Therapists on Staff $(\mathrm{N}=33)$.

3. Modalities Used by Occupational Therapists with Recreational Therapists on Staff $(\mathrm{N}=39)$.

4. Major Goals Rated by Importance by Occupational Therapists without Recreational Therapists on Staff $(N=33)$.

5. Major Goals Rated by Importance by Occupational Therapists with Recreational Therapists on Staff $(\mathrm{N}=39)$.

6. Modalities Used by Recreational Therapists without Occupational Therapists on Staff $(\mathrm{N}=9)$.

7. Modalities Used by Recreational Therapists with Occupational Therapists on Staff ( $N=18)$.

8. Major Goals Rated by Importance by Recreational Therapists without Occupational Therapists on Staff $(N=9)$.

9. Major Goals Rated by Importance by Recreational Therapists with Occupational Therapists on Staff $(N=18)$

10. Comparison of Modality Use - Both Occupational Therapists $(N=39)$ and Recreational Therapists $(N=18)$ Represented on Staff.

11. Comparison of Modality Use - Occupational Therapists $(N=33)$ or Recreational Therapists $(N=9)$ not Represented on Staff.

12. Comparison of Major Goals by Importance - Both Occupational Therapists $(N=39)$ and Recreational Therapists $(N=18)$ Represented on Staff.

13. Comparison of Major Goals by Importance - Occupational Therapists or Recreational Therapists not Represented on Staff. 


\section{CHAPTER 1}

\section{INTRODUCTION}

\section{Purpose}

The purpose of this research was to determine the type and the extent of role overlap between recreational therapists and occupational therapists who are working in the field of mental health. This role overlap was analyzed by comparing the treatment modalities and goals used by each discipline.

\section{Statement of the Problem}

Role overlap between occupational therapy and other disciplines has become a significant issue in recent years. Occupational therapists share various treatment modalities with physical therapists, recreational therapists, and speech therapists in both physical disability and mental health settings. Several studies have indicated that this role overlap appears to have had an impact on the number of occupational therapists practicing in mental health. The declining percentage of occupational therapists practicing in mental health may be due to feelings that this practice area is "nebulous and not clearly differentiated from other mental health professions" (Cottrell, 1990, p. 199). Some professionals have even speculated that occupational therapy in mental health would disappear entirely as a result of unclear role delineations, increased competition from other professionals for decreased funding, and changes in the health care system" (Bonder, 1987, p. 495).

Fidler, a distinguished advocate for occupational therapy in mental health, recently acknowledged that mental health is a problem area in which all 
professions -- not just occupational therapy -- are struggling to define their role in a changing system (Joe, 1990). Although many factors have been identified as contributing to occupational therapy's increasing attrition from the field of mental health, the overlapping of roles between professions may be a source of conflict. One source of conflict that has resulted from this overlap is resistance from recreational therapists toward occupational therapy's attempts to attain licensure in the state of California. Recreational therapists have challenged the inclusion of the word "leisure" in occupational therapy's proposed licensure bill, arguing that the use of leisure activities is strictly their territory. A major outcome of this role overlap may be that unfilled mental health positions are being filled by other rehabilitation professionals. This means that when an occupational therapist leaves a position, a recreation, art, music or dance therapist may be hired as a replacement when there are no other occupational therapists immediately available. It is therefore probable that many administrators in psychiatric facilities have difficulty distinguishing occupational therapy roles from the roles of other professionals, and would be more apt to hire the less expensive recreation therapists if they are perceived to be performing basically the same functions as occupational therapists. Research into this role overlap will provide more objective information in regard to how occupational therapy and recreational therapy are similar to and/or different from one another in mental health settings.

\section{Objectives}

The objectives of this study were:

1. To determine the extent of role overlap between occupational therapists and recreational therapists practicing in the field of mental health. 
2. To determine whether uniqueness exists that is specific to occupational therapy and recreational therapy.

Questions

The questions of this study were as follows:

1. What are the treatment modalities used by occupational therapists and recreational therapists in mental health settings?

2. What are the major goals of therapy as indicated for occupational therapists and recreational therapists in mental health settings?

Definitions

For the purpose of this study, the following definitions were used:

1. Major goals of therapy: desired results of the treatment program as specified by therapists for their mentally ill patients.

2. Mental health settings: locations where treatment programs are carried out for the mentally ill patient.

3. Occupational therapy: therapeutic use of self-care, work and play activities to increase independent function, enhance development, and prevent disability. May include adaptation of task or environment to achieve maximum independence and to enhance quality of life (Hopkins, 1988, p. 4).

4. Recreational therapy: the provision of treatment services and the provision of recreation services to persons with illnesses or disabling conditions (ATRA, 1987).

5. Role overlap: duplication of services by two or more professions.

6. Treatment modalities: methods which are used to assist in the recovery of the mentally ill client. 
7. Uniqueness: a characteristic in which certain treatment modalities and/or goals of therapy are exclusively used by one discipline or another.

\section{Assumptions}

The assumptions held for this study were:

1. There would be overlap in the treatment modalities used by occupational therapists and recreational therapists in mental health settings.

2. Respondents would provide accurate information.

3. In facilities with both occupational therapists and recreational therapists there would be less modality overlap than in facilities employing just one of the disciplines.

\section{Limitations}

The main limitation of this study is the limited geographical area surveyed. The number of subjects is small in comparison to the total number of occupational therapists and recreational therapists in mental health settings in the United States, preventing generalization of the results to a larger population. Another limitation is the possibility that some of the items on the questionnaire may have been misunderstood or misinterpreted due to different terminology used throughout different facilities and regional areas. Also, the list of treatment modalities and goals on the proposed questionnaire may not be all-inclusive.

There is the possibility that subjects were not truthful in their responses, or that they responded according to the perceived expectations of the researcher. The final limitation is that the sample size of recreational therapists was considerably smaller than the sample size of occupational therapists, which may have affected the validity of the results. 


\section{Significance of the Study}

Because of the recent budget cuts in mental health, it has become increasingly important for occupational therapists to demonstrate the efficacy of therapy and the importance of their role in mental health facilities. Occupational therapy positions could be phased out in psychiatric facilities entirely if occupational therapists do not demonstrate their unique and indispensable role in the overall treatment of the mentally ill population. This study is significant in that it will attempt to determine if role overlap between occupational therapists and recreational therapists is a common problem in mental health settings. After a thorough search of the literature it was found that no other research has been done in this area. 


\section{CHAPTER 2}

\section{REVIEW OF THE LITERATURE}

The literature review for this research examines the background of occupational therapy and of recreational therapy, the roles of occupational therapists and recreational therapists in mental health settings, and the effects of role overlap on occupational therapists.

\section{Background of Occupational Therapy}

Occupational therapy's philosophical roots go back to the period of moral treatment in early nineteenth century America. The moral treatment movement brought a disciplined and humanistic perspective to the care of the mentally ill. This perspective was based on the idea that individuals with mental illness need to be engaged in creative and recreational activity with their fellow citizens. Work, exercise, games, and arts and crafts were regularly prescribed as therapeutic activities. According to Evans (1985), "the founding of occupational therapy in the early 1900 's had historical roots in the noted healing potential of activities" (p. 799).

"Occupational therapy is based on the belief that performance of an activity which has purpose and meaning to the individual promotes learning, adaptation, and change. Occupation, or that which engages time and attention, is used by the occupational therapy personnel to prevent and mediate dysfunction and to promote maximum adaptation and function" (Evans, 1985, p. 799). Occupational therapy personnel facilitate the development of interpersonal relationships and promote a balance between work, playfeisure, 
and daily living skills. The occupational therapist must select activities that simultaneously provide successful motivating experiences and the remediation of dysfunctional performance (Evans, 1985).

Roles of the Occupational Therapist

The roles of the occupational therapist within a mental health setting include screening, assessment, program planning, and program implementation. Initial screening is performed to identify the need for occupational therapy intervention, assessments are used to determine the individual's level of function, program planning is the stage when short-term and long-term goals are established, and program implementation is the actual treatment itself. Program implementation varies depending upon individual patient needs. "The type of setting and the frame of reference of that particular setting will also guide the selection of treatment methods" (Evans, 1985, p. 800). All areas of program implementation are directed towards the performance of skills in the areas of work, play, leisure, and self-maintenance, with an appropriate balance among these. Specific skills might include attentiveness, expression of feelings, cooperation, grooming, time or money management, use of public transportation, work habits, and leisure skills. Techniques to teach these skills might include the use of creative media, games, simulation, or actual skill practice

It appears that role priorities are shifting, however, as some occupational therapists are no longer using such basic activities as crafts, games, and work in treatment due to the lack of credibility that often accompanies use of these activities. (Fidler, 1981). It may even be that many occupational therapists are virtually handing over some of their modalities to other disciplines for this 
reason (Fidler, 1981). As stated by Fidler (1981), "evaluation, assessment, and consultation have come to have priority over the role of implementor. We have relegated or given away our "doing" functions to the OT assistant, the teacher, the creative arts therapist, and the vocational rehabilitator" ( $p .570)$. It then becomes questionable how long occupational therapists can expect to control those functions.

\section{Background of Recreational Therapy}

The contemporary history of the Therapeutic Recreation profession merges from two philosophical positions that developed in the 1940's and 1950 's. One position promoted the use of recreation as a therapeutic tool for treatment, while the other position held that recreation was an end in itself and met a specific human need for those persons who were institutionalized. In the early 1950's the term "therapeutic recreation" was coined to bridge the semantic gap between "recreation therapy" and "hospital recreation" (American Therapeutic Recreation Association, 1987).

\section{Roles of the Recreational Therapist}

The therapeutic recreation process consists of 4 steps: assessment, planning, implementation, and evaluation (Austin, 1991). This process is applied in any setting in which goal-directed programs are desired. From the assessment, the recreational therapist determines the particular needs of the client and establishes goals in the planning phase of the process. The following are examples of goals that may be appropriate in planning for different needs: increasing confidence, learning social or leisure skills, managing stress, improving fitness, enhancing self-esteem, and building positive expectations (Austin, 1991). 
Once goals and objectives have been specified in the individual program plan, the recreational therapist selects activities to apply in the intervention process. A wide variety of modalities are used by recreational therapists, including relaxation techniques, stress management, assertiveness training, sensory training, pet therapy, social skills training, reality orientation, physical activity, horticulture therapy, values clarification, therapeutic touch, and games (Austin, 1991). Evaluation, the final step in the therapeutic recreation process, examines the effectiveness of the client's program so that the therapist can make revisions if necessary.

Effects of Role Overlap on Occupational Therapists

In a pilot study by Cottrell in 1987, 250 occupational therapists practicing in mental health in New York and New Jersey were surveyed to identify their level of perceived competence. The results of this study revealed that, on a rating scale of poor to excellent, $97 \%$ of the study's 95 respondents currently practicing in mental health perceived their ability to describe occupational therapy's role in mental health as "good" or "excellent". Biers and Murphy (1970) found that $41.7 \%$ of the inactive occupational therapists they surveyed identified role ambiguity as a source of job dissatisfaction. This finding suggests that role ambiguity may be a strong deterrent towards commitment to the profession.

Crossing another's territorial boundaries appears to be a source of conflict between disciplines, particularly in mental health where funding is tighter and the need to prove one's efficacy is therefore stronger. In one study, Dickerson and Kaplan (1991) surveyed clinical and academic occupational therapists to compare the specific crafts currently being used in psychiatric occupational 
therapy clinics with the craft modalities being taught in occupational therapy curricula. Two questionnaires were constructed, one for each subject group. The clinical questionnaire was sent to 1000 subjects drawn randomly from the national member list of AOTA's June 1989 Mental Health Special Interest Section. The curriculum questionnaires were sent to the program directors of all 139 accredited programs in the United States. Nine of the 339 clinical respondents reported that recreational therapists, art therapists, and aides are using crafts for recreational or diversionary activities. Two of the respondents specifically mentioned having some territorial difficulties with other disciplines. Twenty-one respondents reported that life skills-type groups are replacing crafts as the most frequently used treatment modalities, and many attributed this change in modality use to increased professional credibility.

According to Beth Rollinger, OTR (Mastrangelo, 1991), "'many times unnecessary duplication occurs because of lack of understanding of the unique contribution of each of the allied health professionals. One reason for this poor understanding is lack of standardized definitions and delineated roles among these professionals"' (p. 18). As stated by Barris, Kielhofner and Watts (1983), "The occupational therapist must know the language of and share concepts with several disciplines and frames of reference, while at the same time offering a unique and focused contribution to the health care of psychosocially dysfunctional people. This complex task can be exacerbated when there is a lack of consensus about what the field's unique role is or whether such a role even exists" (p. 168). When there is a lack of consensus among occupational therapists as to their own unique role in treatment, there would presumably be a great deal of confusion among other health care professionals as to the role of 
occupational therapists. This lack of understanding of occupational therapy may lead to incorrect or fewer referrals to occupational therapy by other professionals.

A study by Florian and Sacks (1985) sought to discover the main reasons why four professional groups -- physicians, nurses, physical therapists, and mental health professionals -- referred patients to occupational therapy services. This study surveyed 162 subjects using a questionnaire listing various reasons for referral. There was a considerable lack of consensus among the different groups as to their beliefs regarding the roles of occupational therapists. The three most frequently cited reasons for referring patients to occupational therapy units were: occupational therapy is a part of the general medical treatment (95\%), occupational therapy helps in the diagnosis of physical and mental conditions (93\%), and occupational therapy helps improve specific physical functions $(90 \%)$. Physicians and mental health professionals appear to refer patients to occupational therapy mainly for reasons involving the patients' capacity to express their skills and abilities and succeed in practical experiences. On the other hand, physical therapists and nurses tended to emphasize the improvement of specific physical functions in daily living activities (Florian \& Sacks, 1985).

Because of the role ambiguity between disciplines, reimbursement appears to be a problem for many occupational therapists. As funding becomes tighter, federal and state funds for treatment of mental illness are being divided among an increasing number of mental health professionals. Also, private insurers are now only providing coverage for those services that can supply cost and utilization information. As a result, if others do not understand the 
important and distinct role played by occupational therapy in mental health, occupational therapists must prove their effectiveness in treatment to justify reimbursement. Depending on the system and the budget process of individual facilities, occupational therapy services may be lumped together with other therapies and then labelled as activity therapy, rather than an individual line item, in the facility budget. Combining different therapies under one name promotes role blurring, and it becomes difficult to pinpoint the contributions of each therapist in terms of treatment. Furthermore, when claims are submitted to insurers for services performed by occupational therapists, revenue may not be credited to occupational therapy, but to activity therapy. Occupational therapy services must be differentiated from other therapies in order to improve reimbursement status (Peters, 1984).

\section{Summary}

The profession of occupational therapy overlaps with at least 15 other professions in the areas of work, school, self-care, playfleisure, and creative/performing arts. Exclusive to the occupational therapist must be the basic knowledge of occupation. "It is that knowledge which permits the occupational therapist to look at an activity of daily living in a unique way, and so determine best how to facilitate the patient's or client's goal achievement" (Wiemer, 1979).

As gathered from this literature review, it appears that role overlap with other disciplines has created some difficulties in practice. Because of the budget cuts in mental health, occupational therapists feel pressured to show the efficacy of and justify their treatments, which is partially due to increased competition with other professionals. There appears to be some confusion 
among physicians and others as to the role of occupational therapy, as indicated by the wide variety of reasons given for referral. Problems with reimbursement have also been a result of the role ambiguity between disciplines. Billing occupational therapy together with other therapies under an all-encompassing title only promotes role blurring, though it is certainly more convenient for billing purposes. Despite a thorough search of the recreational therapy literature, no information could be found that addressed role overlap between occupational therapists and recreational therapists working in mental health. 


\section{CHAPTER 3}

\section{METHODOLOGY AND RESULTS}

The study was conducted as descriptive research using survey methodology to collect the data.

Questions

The following questions guided this research:

1. What are the treatment modalities used by occupational therapists and recreational therapists in mental health settings?

2. What are the major goals of therapy as indicated for occupational therapists and recreational therapists in mental health settings?

Objectives

The objectives of the study were:

1. To determine the extent of role overlap between occupational therapists and recreational therapists practicing in the field of mental health.

2. To determine whether uniqueness exists that is specific to occupational therapy and recreational therapy.

\section{Sample}

The sample consisted of 149 occupational therapists and 56 recreational therapists who currently are or have been employed in mental health settings throughout the state of California. The sample of 149 occupational therapists was obtained from the American Occupational Therapy Association of current members of the mental health special interest section. The sample of 56 recreational therapists was obtained from the American Therapeutic Recreation 
Association (39 subjects) and the California Parks and Recreation Society (17 subjects), all of whom were designated as currently working in mental health.

Data Collection

Data were gathered by a self-report questionnaire (Appendix A). The content of the questionnaire was organized into three sections: general information, modalities, and goals. General information requested included: type of setting, primary population treated, and other activity therapy disciplines represented on staff. A total of $\mathbf{3 2}$ modalities were listed in the modalities section, and respondents were asked to indicate the frequency (usually, sometimes, or never) with which they use each one in treatment. A majority of the modalities were taken from a questionnaire used in a study by Pedretti and Glogoski (1988) to determine the methods, activities, and skills used in occupational therapy practice. Other modalities included in the questionnaire had been utilized in the researcher's psychiatric fieldwork experience. Twelve goals which had been commonly used in the researcher's psychiatric fieldwork experience were listed in the goal section of the questionnaire. Respondents were asked to rate each goal on a scale of 1 to $5(1=$ very important, $5=$ not important) in terms of its importance in their treatment planning. There was no reliability or validity established for the questionnaire.

A cover letter (Appendix B) explaining the purpose of the study and a self addressed stamped envelope were mailed along with each questionnaire. The cover letter assured that all information provided would be confidential. Survey recipients were asked to return the questionnaire within a two week period. 


\section{Data Analysis Procedures}

Descriptive data analysis techniques were used for this study. Tallies were done to obtain modality frequencies and goal ratings. Then, percentages were calculated for "usually" responses for each modality and for "very important" ratings for each goal. The percentages for occupational therapists were compared with percentages for recreational therapists. The differences in percentages were calculated for each modality and for each goal and were labeled as "\% overlap."

A total of 205 questionnaires were mailed, 149 to occupational therapists and 56 to recreational therapists. Seventy-eight $(52 \%)$ of the 149 occupational therapists and twenty-eight $(50 \%)$ of the 56 recreational therapists responded to the survey, with $72(48 \%)$ of the 149 occupational therapists and $27(48 \%)$ of the 56 recreational therapists providing usable data for analysis.

\section{Demographic Data}

The respondents to the survey were occupational therapists and recreational therapists who currently are or have been employed in mental health settings in the state of California. Of the occupational therapists who responded, two were presently retired, one was unemployed, one was currently working in physical disabilities, and 68 were currently employed in mental health. The four respondents not currently working in the mental health field completed the questionnaire according to their most recent position held in a mental health setting and their data were included in analysis. All of the recreational therapists who responded were currently employed in mental health facilities. 
In the first section of the questionnaire, respondents were asked to provide the following information: (1) type of mental health setting, (2) primary population treated, and (3) other activity therapy disciplines on staff. Table 1 illustrates the distribution of therapists by types of settings in which each group of respondents is or was employed. The majority of both groups $(64 \%$ of occupational therapists and $93 \%$ of recreational therapists) indicated hospital based settings as their place of employment. Several of the respondents indicated more than one setting in which they were employed, all of which were included in the results. In the "other" category, responses included the following: a state owned and operated developmental center, department of corrections, private practice, private school for the learning disabled, and a locked sub-acute facility with open group home.

Both groups of respondents indicated adults as their primary population treated. However, some of the respondents in each group had experience with children and adolescents.

Other activity therapy disciplines which were commonly represented in the respondents' facilities are art therapists and music therapists. Other disciplines reported by respondents included dance/movement therapists, activity therapists, drama therapists, kinesiotherapist, and horticulture therapists. Sixty-seven percent of the recreational therapists reported that occupational therapists are on staff in their facilities, whereas 33\% of them reported no occupational therapists on staff. Fifty-four percent of the occupational therapists reported that recreational therapists are on staff in their facility, whereas $46 \%$ of them reported no recreational therapists on staff. 
Table 1

Type of Mental Health Setting in which Respondents Practice

Occupational Therapists Recreational Therapists

\begin{tabular}{lrrrr} 
Setting & $\underline{\mathrm{n}}$ & $\%$ & $\underline{\mathrm{n}}$ & $\%$ \\
\hline Hospital based & 46 & 64 & 25 & 93 \\
Community based & 9 & 13 & 1 & 4 \\
Day treatment & 16 & 22 & 1 & 4 \\
Other & 5 & 7 & 2 & 7 \\
\hline
\end{tabular}

Note. Other settings listed by occupational therapists were: a state owned and operated developmental center, a private school for the Learning Disabled, department of corrections, private practice, and a residential treatment center; other settings listed by recreational therapists include a locked sub-acute facility with open group home, and a state developmental center. 


\section{Modality Use by Occupational Therapists}

Respondents were asked to rank a list of 32 modalities as either usually, sometimes, or never used in practice. Data are reported separately by occupational therapists who work with recreational therapists. Table 2 presents the data provided by those occupational therapists who indicated that they do not work with recreational therapists. Table 3 presents modality frequencies of those occupational therapists who work with recreational therapists. The modalities reported as "usually" used in practice by the majority of occupational therapists who do not work with recreational therapists are stress management, woodwork, cooking/meal planning, time management, leisure planning, leatherwork, and social outings. The modalities indicated as "usually" used in practice by the majority of occupational therapists who work with recreational therapists are stress management, leatherwork, tile mosaics, paper crafts, ceramics, copper tooling, woodwork, and assertiveness training.

Goals Reported by Occupational Therapists

The major goals reported by occupational therapists who work with recreatonal therapists are as follows: increase attention span, increase communication skills, increase purposeful activity, increase self esteem, increase problem solving, increase socialization skills, increase frustration tolerance, increase motivation level, and increase performance tolerance. Table 4 presents the ratings by importance for each of the goals on the questionnaire by this group of occupational therapists.

The major goals reported by occupational therapists who do not work with recreational therapists are as follows: increase attention span, increase 
Table 2

Modalities Used by Occupational Therapists without Recreational Therapists on Staff $(N=33)$

\begin{tabular}{lcccc} 
Modality & Usually & Sometimes & Never & No response \\
\hline Stress management training & 20 & 9 & 4 & 0 \\
Woodwork & 19 & 8 & 4 & 2 \\
Time management & 18 & 15 & 0 & 0 \\
Leisure planning & 18 & 14 & 0 & 1 \\
Cooking/meal planning & 18 & 10 & 3 & 2 \\
Leatherwork & 17 & 11 & 3 & 5 \\
Social outings & 17 & 11 & 3 & 5 \\
Grooming/hygiene skills & 15 & 16 & 2 & 0 \\
Ceramics/pottery & 15 & 10 & 6 & 2 \\
Tile mosaics & 15 & 7 & 9 & 2 \\
Assertiveness training & 14 & 14 & 4 & 1 \\
Home/personal safety & 13 & 18 & 2 & 0 \\
Money management & 11 & 20 & 2 & 0 \\
Tabletop games & 11 & 17 & 4 & 1 \\
Physical games/sports & 10 & 17 & 4 & 2 \\
Copper tooling & 9 & 14 & 7 & 3 \\
Shopping & 9 & 14 & 9 & 1 \\
& & & continued...
\end{tabular}


Table 2

(continued)

Results of Modality Use by Occupational Therapists without Recreational Therapists on Staff $(\mathrm{N}=33)$

Modality Usually Sometimes Never No response

\begin{tabular}{lllll}
\hline Paper crafts & 8 & 20 & 3 & 2 \\
Jewelry making & 8 & 17 & 6 & 2 \\
Decoupage & 7 & 17 & 7 & 2 \\
Water color & 6 & 21 & 3 & 3 \\
Tempera/acrylics & 6 & 21 & 4 & 2 \\
Needlecrafts & 6 & 18 & 7 & 2 \\
Stained glass & 6 & 11 & 14 & 2 \\
Electronic equipment (VCR's, & 5 & 12 & 13 & 3 \\
camcorders, computers, etc.) & & & & \\
Stenciling & 4 & 20 & 7 & 2 \\
Finger painting & 4 & 11 & 16 & 2 \\
Printing & 1 & 10 & 18 & 4 \\
Tie dying & 1 & 8 & 20 & 4 \\
Basketry & 1 & 6 & 23 & 3 \\
Oil painting & 0 & 12 & 17 & 4 \\
Silk screening & 0 & 3 & 26 & 4
\end{tabular}


Table 3

Modalities Used by Occupational Therapists with Recreational Therapists on

Staff $(N=39)$

\begin{tabular}{lcccc} 
Modality & Usually & Sometimes & Never & No response \\
\hline Stress management training & 21 & 13 & 3 & 2 \\
Leatherwork & 20 & 11 & 5 & 3 \\
Tile mosaics & 19 & 11 & 6 & 3 \\
Paper crafts & 18 & 15 & 4 & 2 \\
Ceramics/pottery & 17 & 14 & 6 & 2 \\
Assertiveness training & 16 & 17 & 4 & 2 \\
Woodwork & 16 & 15 & 5 & 3 \\
Copper tooling & 16 & 15 & 5 & 3 \\
Leisure planning & 15 & 19 & 4 & 1 \\
Time management & 15 & 17 & 5 & 2 \\
Social outings & 15 & 12 & 10 & 2 \\
Decoupage & 12 & 16 & 8 & 3 \\
Tabletop games & 11 & 15 & 11 & 2 \\
Stained glass & 11 & 6 & 19 & 3 \\
Grooming/hygiene skills & 10 & 25 & 3 & 1 \\
Needlecrafts & 10 & 22 & 4 & 3 \\
Tempera/acrylics & 10 & 21 & 6 & 2 \\
& & & continued...
\end{tabular}


Table 3

(continued)

Modalities Used by Occupational Therapists with Recreational Therapists on

Staff $(N=39)$

\begin{tabular}{|c|c|c|c|c|}
\hline Modality & Usually & Sometimes & Never & No response \\
\hline Physical games/sports & 10 & 18 & 10 & 1 \\
\hline Home/personal safety & 9 & 20 & 8 & 2 \\
\hline Cooking/meal planning & 8 & 20 & 9 & 2 \\
\hline Shopping & 7 & 17 & 14 & 1 \\
\hline Stenciling & 7 & 16 & 13 & 3 \\
\hline Money management & 6 & 24 & 7 & 2 \\
\hline Jewelry making & 6 & 19 & 12 & 2 \\
\hline Water color & 5 & 24 & 8 & 2 \\
\hline $\begin{array}{l}\text { Electronic equipment (VCR's, } \\
\text { camcorders, computers, etc.) }\end{array}$ & 5 & 11 & 21 & 2 \\
\hline Finger painting & 3 & 17 & 18 & 1 \\
\hline Basketry & 2 & 18 & 16 & 3 \\
\hline Oil painting & 2 & 10 & 24 & 3 \\
\hline Tie dying & 1 & 11 & 25 & 2 \\
\hline Printing & 0 & 8 & 28 & 3 \\
\hline Silk screening & 0 & 2 & 34 & 3 \\
\hline
\end{tabular}


Table 4

Major Goals Rated by Importance by Occupational Therapists without

Recreational Therapists on Staff $(\mathrm{N}=33)$

Rating by Importance

\begin{tabular}{lcccccc} 
Goal & $1^{*}$ & 2 & 3 & 4 & $5^{* *}$ \\
\hline Increase problem solving & 27 & 4 & 0 & 1 & 1 \\
Increase self esteem & 24 & 7 & 0 & 0 & 2 \\
Increase communication skills & 23 & 8 & 0 & 0 & 2 \\
Increase attention span/concentration & 22 & 6 & 3 & 1 & 1 \\
Increase socialization skills & 21 & 9 & 1 & 0 & 2 \\
Increase performance tolerance & 21 & 7 & 2 & 2 & 1 \\
Increase purposeful activity & 19 & 10 & 1 & 1 & 2 \\
Increase motivation level & 18 & 9 & 4 & 0 & 2 \\
Increase frustration tolerance & 18 & 8 & 5 & 1 & 1 \\
Increase independence in daily & 15 & 9 & 4 & 4 & 1 \\
living skills & & & & & \\
Increase relaxation skills & 8 & 16 & 5 & 2 & 1 \\
Increase leisure planning & 8 & 7 & 14 & 4 & 0
\end{tabular}

"very important

" not important 
communication skills, increase purposeful activity, increase seff esteem, increase problem solving, increase socialization skills, increase frustration tolerance, increase motivation level, and increase performance tolerance. Table 5 presents the ratings by importance for each of the goals on the questionnaire by this group of occupational therapists.

Modality Use by Recreational Therapists

Table 6 presents modality frequencies of recreational therapists who do not work with occupational therapists. Table 7 presents modality frequencies of those recreational therapists who work with occupational therapists. The modalities reported as "usually" used in practice by the majority of recreational therapists who do not work with occupational therapists are leisure planning, physical games/sports and stress management training. The modalities indicated as "usually" used in practice by the majority of recreational therapists who work with occupational therapists are leisure planning, physical games/sports, stress management training, tabletop games, and social outings.

Goals Reported by Recreational Therapists

The major goals reported by recreational therapists who do not work with occupational therapists are as follows: increase communication skills, increase purposeful activity, increase self esteem, increase socialization skills, increase leisure planning, increase frustration tolerance, increase motivation level, and increase relaxation skills. Table 8 presents the ratings by importance for each of the goals by this group of recreational therapists. The major goals reported by recreational therapists who work with occupational therapists are as follows: increase attention span, increase communication skills, increase purposeful 
Table 5

Major Goals Rated by Importance by Occupational Therapists with Recreational Therapists on Staff $(\mathrm{N}=39)$

\begin{tabular}{lrrrrr}
\hline & \multicolumn{5}{c}{ Rating by Importance } \\
\cline { 2 - 7 } Goal & $1^{*}$ & 2 & 3 & 4 & $5^{* *}$ \\
\hline Increase communication skills & 30 & 3 & 0 & 1 & 4 \\
Increase problem solving & 29 & 3 & 2 & 0 & 4 \\
Increase self esteem & 28 & 4 & 3 & 0 & 3 \\
Increase attention span/concentration & 26 & 4 & 3 & 2 & 2 \\
Increase frustration tolerance & 25 & 5 & 1 & 2 & 4 \\
Increase performance tolerance & 24 & 5 & 4 & 1 & 3 \\
Increase socialization skills & 23 & 10 & 1 & 0 & 4 \\
Increase purposeful activity & 23 & 9 & 3 & 1 & 1 \\
Increase motivation level & 23 & 6 & 5 & 2 & 1 \\
Increase independence in daily & 11 & 9 & 11 & 4 & 2 \\
living skills & 9 & 18 & 6 & 3 & 1 \\
Increase relaxation skills & 5 & 13 & 14 & 5 & 0 \\
Increase leisure planning & & & & & \\
\hline
\end{tabular}

"very important

" not important 
Table 6

Modalities Used by Recreational Therapists without Occupational Therapists on Staff $(N=9)$

\begin{tabular}{|c|c|c|c|c|}
\hline Modality & Usually & Sometimes & Never & No response \\
\hline Leisure planning & 7 & 2 & 0 & 0 \\
\hline Physical games/sports & 7 & 2 & 0 & 0 \\
\hline Stress management training & 5 & 3 & 1 & 0 \\
\hline Time management & 4 & 4 & 1 & 0 \\
\hline Ceramics/pottery & 4 & 4 & 1 & 0 \\
\hline Social outings & 4 & 3 & 1 & 1 \\
\hline Water color & 4 & 3 & 2 & 0 \\
\hline Needlecrafts & 3 & 5 & 1 & 0 \\
\hline Tabletop games & 3 & 5 & 1 & 0 \\
\hline Woodwork & 3 & 4 & 2 & 0 \\
\hline Assertiveness training & 3 & 4 & 2 & 0 \\
\hline Tempera/acrylics & 3 & 4 & 2 & 0 \\
\hline Finger painting & 3 & 4 & 2 & 0 \\
\hline Leatherwork & 3 & 3 & 3 & 0 \\
\hline $\begin{array}{l}\text { Electronic equipment (VCR's, } \\
\text { camcorders, computers, etc.) }\end{array}$ & 2 & 4 & 3 & 0 \\
\hline Paper crafts & 1 & 7 & 1 & 0 \\
\hline Jewelry making & 1 & 5 & 3 & $\begin{array}{c}0 \\
\text { ontinued... }\end{array}$ \\
\hline
\end{tabular}


Table 6

(continued)

Modalities Used by Recreational Therapists without Occupational Therapists on

Staff $(N=9)$

Modality Usually Sometimes Never No response

Money management

5

3

0

Cooking/meal planning

5

3

0

Tile mosaics

1

4

4

0

Decoupage

1

3

5

0

Grooming/hygiene skills

1

2

6

0

Stained glass

1

2

6

0

Oil painting

1

2

6

0

Shopping

0

8

1

0

Home/personal safety

0

5

Stenciling

0

5

4

0

Tie dying

0

5

4

0

Copper tooling

0

5

4

0

Printing

0

4

4

0

Basketry

0

3

5

0

Silk screening

0

2

6

0

70 
Table 7

Modalities Used by Recreational Therapists with Occupational Therapists on

Staff $(N=18)$

\begin{tabular}{|c|c|c|c|c|}
\hline Modality & Usually & Sometimes & Never & No response \\
\hline Leisure planning & 15 & 3 & 0 & 0 \\
\hline Physical games/sports & 14 & 4 & 0 & 0 \\
\hline Tabletop games & 13 & 5 & 0 & 0 \\
\hline Stress management training & 13 & 5 & 0 & 0 \\
\hline Social outings & 12 & 3 & 2 & 1 \\
\hline Cooking/meal planning & 9 & 6 & 3 & 0 \\
\hline Time management & 9 & 5 & 3 & 1 \\
\hline $\begin{array}{l}\text { Electronic equipment (VCR's, } \\
\text { camcorders, computers, etc.) }\end{array}$ & 8 & 9 & 1 & 0 \\
\hline Assertiveness training & 7 & 8 & 3 & 0 \\
\hline Money management & 6 & 7 & 5 & 0 \\
\hline Ceramics/pottery & 6 & 6 & 6 & 0 \\
\hline Home/personal safety & 5 & 8 & 5 & 0 \\
\hline Grooming/hygiene skills & 5 & 5 & 7 & 1 \\
\hline Shopping & 5 & 5 & 8 & 0 \\
\hline Needlecrafts & 5 & 3 & 10 & 0 \\
\hline Water color & 4 & 10 & 4 & 0 \\
\hline Tempera/acrylics & 4 & 8 & 4 & 2 \\
\hline
\end{tabular}


Table 7

(continued)

Modalities Used by Recreational Therapists with Occupational Therapists on

Staff $(N=18)$

\begin{tabular}{lcccc}
\hline Modality & Usually & Sometimes & Never & No response \\
\hline Leatherwork & 4 & 6 & 8 & 0 \\
Printing & 4 & 6 & 8 & 0 \\
Woodwork & 4 & 4 & 10 & 0 \\
Paper crafts & 3 & 11 & 4 & 0 \\
Tile mosaics & 3 & 7 & 8 & 0 \\
Stained glass & 3 & 6 & 9 & 0 \\
Stenciling & 3 & 5 & 10 & 0 \\
Copper tooling & 3 & 4 & 11 & 0 \\
Decoupage & 2 & 8 & 8 & 0 \\
Jewelry making & 1 & 10 & 7 & 0 \\
Tie dying & 1 & 4 & 13 & 0 \\
Oil painting & 1 & 3 & 14 & 0 \\
Basketry & 0 & 5 & 11 & 2 \\
Finger painting & 0 & 5 & 13 & 0 \\
Silk screening & 0 & 1 & 17 & 0
\end{tabular}


Table 8

Major Goals Rated by Importance by Recreational Therapists without

Occupational Therapists on Staff $(N=9)$

Rating by Importance

\begin{tabular}{llllll} 
Goal & $1^{*}$ & 2 & 3 & 4 & $5^{* *}$ \\
\hline Increase self esteem & 9 & 0 & 0 & 0 & 0 \\
Increase socialization skills & 8 & 0 & 0 & 1 & 0 \\
Increase communication skills & 6 & 1 & 2 & 0 & 0 \\
Increase leisure planning & 6 & 2 & 0 & 1 & 0 \\
Increase frustration tolerance & 6 & 1 & 1 & 0 & 1 \\
Increase purposeful activity & 5 & 3 & 0 & 1 & 0 \\
Increase motivation level & 5 & 3 & 1 & 0 & 0 \\
Increase relaxation skills & 5 & 4 & 0 & 0 & 0 \\
Increase problem solving & 4 & 3 & 2 & 0 & 0 \\
Increase attention span/concentration & 3 & 3 & 2 & 1 & 0 \\
Increase performance tolerance & 3 & 1 & 3 & 2 & 0 \\
Increase independence in daily & 1 & 3 & 1 & 2 & 2
\end{tabular}

*very important

" not important 
activity, increase self esteem, increase problem solving, increase socialization skills, increase leisure planning, increase frustration tolerance, and increase motivation level. Table 9 presents the ratings by importance for each of the goals by this group of recreational therapists.

\section{Comparison of Modality Use}

Modality use by occupational therapists and recreational therapists was compared in two separate categories: (1) facilities in which respondents indicated that both disciplines are represented on staff, and (2) facilities in which respondents indicated that the other discipline was not represented on staff. Results from the first category of comparisons, in which both occupational therapy and recreational therapy are represented in the facility, are presented in Table 10. Those modalities in which there were 0 "usually" responses by occupational therapists and/or recreational therapists were not included in the comparison results. There was only $1 \%$ of overlap between occupational therapists and recreational therapists in the use of stenciling, with $18 \%$ of occupational therapists and $17 \%$ of recreational therapists indicating "usually" for this modality. Other modalities in which the percent of overlap was small (5\% or less) include grooming, assertiveness training, needlecrafts, tie dying, and home/personal safety.

In the category in which either occupational therapy or recreational therapy is not represented in the facility, slightly different results were found. These results are presented in Table 11. There was $0 \%$ of overlap in the use of tabletop games, in which an equal percentage of occupational therapists and recreational therapists (33\%) indicated "usually" for this modality. Other 
Table 9

Major Goals Rated by Importance by Recreational Therapists with Occupational Therapists on Staff $(N=18)$

\begin{tabular}{|c|c|c|c|c|c|}
\hline \multirow[b]{2}{*}{ Goal } & \multicolumn{5}{|c|}{ Rating by Importance } \\
\hline & $1^{*}$ & 2 & 3 & 4 & $5^{* *}$ \\
\hline Increase socialization skills & 14 & 2 & 2 & 0 & 0 \\
\hline Increase self esteem & 14 & 1 & 3 & 0 & 0 \\
\hline Increase communication skills & 13 & 2 & 3 & 0 & 0 \\
\hline Increase attention span & 13 & 2 & 3 & 0 & 0 \\
\hline Increase leisure planning & 13 & 0 & 4 & 0 & 0 \\
\hline Increase problem solving & 11 & 5 & 2 & 0 & 0 \\
\hline Increase purposeful activity & 11 & 4 & 3 & 0 & 0 \\
\hline Increase motivation level & 11 & 3 & 3 & 0 & 0 \\
\hline Increase frustration tolerance & 10 & 4 & 3 & 0 & 0 \\
\hline Increase relaxation skills & 9 & 5 & 3 & 0 & 0 \\
\hline $\begin{array}{l}\text { Increase independence in daily } \\
\text { living skills }\end{array}$ & 5 & 1 & 7 & 3 & 0 \\
\hline Increase performance tolerance & 4 & 10 & 2 & 1 & 0 \\
\hline
\end{tabular}

"very important

" not important 
Table 10

Comparison of Modality Use - Both Occupational Therapists $(N=39)$ and

Recreational Therapists $(N=18)$ Represented on Staff

\begin{tabular}{|c|c|c|c|c|c|}
\hline \multirow[b]{2}{*}{ Modality } & \multicolumn{2}{|c|}{ OT } & \multicolumn{2}{|c|}{ RT } & \multirow[b]{2}{*}{$\%$ Overlap } \\
\hline & $\underline{n}$ & $\%$ & $\underline{\mathrm{n}}$ & $\%$ & \\
\hline Stenciling & 7 & 18 & 3 & 17 & 1 \\
\hline Grooming/hygiene skills & 10 & 26 & 5 & 28 & 2 \\
\hline Assertiveness training & 16 & 41 & 7 & 39 & 2 \\
\hline Needleciafts & 10 & 26 & 5 & 28 & 2 \\
\hline Tie dying & 1 & 3 & 1 & 6 & 3 \\
\hline Tempera/acrylics & 10 & 26 & 4 & 22 & 4 \\
\hline Home/personal safety & 9 & 23 & 5 & 28 & 5 \\
\hline Jewelry making & 6 & 15 & 1 & 6 & 9 \\
\hline Water color & 5 & 13 & 4 & 22 & 9 \\
\hline Shopping & 7 & 18 & 5 & 28 & 10 \\
\hline Ceramics/pottery & 17 & 44 & 6 & 33 & 11 \\
\hline Stained glass & 11 & 28 & 3 & 17 & 11 \\
\hline Time management & 15 & 38 & 9 & 50 & 12 \\
\hline Money management & 6 & 15 & 6 & 33 & 18 \\
\hline Stress management & 21 & 54 & 13 & 72 & $\begin{array}{c}18 \\
\text { continued. }\end{array}$ \\
\hline
\end{tabular}


Table 10

(continued)

Comparison of Modality Use - Both Occupational Therapists (N =39) and

Recreational Therapists $(N=18)$ Represented on Staff

\begin{tabular}{|c|c|c|c|c|c|}
\hline \multirow[b]{2}{*}{ Modality } & \multicolumn{2}{|c|}{ OT } & \multicolumn{2}{|l|}{ RT } & \multirow[b]{2}{*}{$\%$ Overlap } \\
\hline & $\underline{\mathrm{n}}$ & $\%$ & $\underline{n}$ & $\%$ & \\
\hline Woodwork & 16 & 41 & 4 & 22 & 19 \\
\hline Decoupage & 12 & 31 & 2 & 11 & 20 \\
\hline Copper tooling & 16 & 41 & 3 & 17 & 24 \\
\hline Cooking/meal planning & 8 & 21 & 9 & 50 & 29 \\
\hline Leatherwork & 20 & 51 & 4 & 22 & 29 \\
\hline Paper crafts & 18 & 46 & 3 & 17 & 29 \\
\hline Social outings & 15 & 38 & 12 & 67 & 29 \\
\hline Electronic equipment & 5 & 13 & 8 & 44 & 31 \\
\hline Tile mosaics & 19 & 49 & 3 & 17 & 32 \\
\hline Tabletop games & 11 & 28 & 13 & 72 & 44 \\
\hline Leisure planning & 15 & 38 & 15 & 83 & 45 \\
\hline Physical games/sports & 10 & 26 & 14 & 78 & 52 \\
\hline
\end{tabular}


Table 11

Comparison of Modality Use - Occupational Therapists $(N=33)$ or Recreational

Therapists ( $N=9)$ not Represented on Staff

\begin{tabular}{|c|c|c|c|c|c|}
\hline \multirow[b]{2}{*}{ Modality } & \multicolumn{2}{|c|}{ OT } & \multicolumn{2}{|c|}{ RT } & \multirow[b]{2}{*}{$\%$ Overlap } \\
\hline & $\underline{n}$ & $\%$ & $\underline{n}$ & $\%$ & \\
\hline Tabletop games & 11 & 33 & 3 & 33 & 0 \\
\hline Ceramics/pottery & 15 & 45 & 4 & 44 & 1 \\
\hline Stress management & 20 & 61 & 5 & 56 & 5 \\
\hline Electronic equipment & 5 & 15 & 2 & 22 & 7 \\
\hline Stained glass & 6 & 18 & 1 & 11 & 7 \\
\hline Social outings & 17 & 52 & 4 & 44 & 8 \\
\hline Assertiveness training & 14 & 42 & 3 & 33 & 9 \\
\hline Decoupage & 7 & 21 & 1 & 11 & 10 \\
\hline Time management & 18 & 55 & 4 & 44 & 11 \\
\hline Oil painting & 0 & 0 & 1 & 11 & 11 \\
\hline Paper crafts & 8 & 24 & 1 & 11 & 13 \\
\hline Jewelry making & 8 & 24 & 1 & 11 & 13 \\
\hline Tempera/acrylics & 6 & 18 & 3 & 33 & 15 \\
\hline Needlecrafts & 6 & 18 & 3 & 33 & 15 \\
\hline Leatherwork & 17 & 52 & 3 & 33 & 19 \\
\hline Finger painting & 4 & 12 & 3 & 33 & 21 \\
\hline
\end{tabular}


Table 11

(continued)

Comparison of Modality Use-Occupational Therapists ( $N=33$ ) or Recreational Therapists ( $N=9$ ) not Represented on Staff

\begin{tabular}{|c|c|c|c|c|c|}
\hline \multirow[b]{2}{*}{ Modality } & \multicolumn{2}{|c|}{ OT } & \multicolumn{2}{|c|}{ RT } & \multirow[b]{2}{*}{$\%$ Overlap } \\
\hline & $\underline{n}$ & $\%$ & $\underline{n}$ & $\%$ & \\
\hline Money management & 11 & 33 & 1 & 11 & 22 \\
\hline Leisure planning & 18 & 55 & 7 & 78 & 23 \\
\hline Woodwork & 19 & 58 & 3 & 33 & 25 \\
\hline Water color & 6 & 18 & 4 & 44 & 26 \\
\hline Grooming/hygiene skills & 15 & 45 & 1 & 11 & 34 \\
\hline Tile mosaics & 15 & 45 & 1 & 11 & 34 \\
\hline Cooking/meal planning & 18 & 55 & 1 & 11 & 44 \\
\hline Physical games/sports & 10 & 30 & 7 & 78 & 48 \\
\hline
\end{tabular}


modalities in which the overlap was $5 \%$ or less were ceramics and stress management training.

\section{Comparison of Major Goals}

Ratings of major goals by importance were also compared according to the two categories used above. Only the "very important" ratings were compared, as these give the best indication of overlap between the two disciplines. In the category in which both occupational therapy and recreational therapy are represented in the facility, the majority of occupational therapists indicated that all of the listed goals with the exceptions of increase leisure planning, increase relaxation skills, and increase independence in daily living skills are very important to treatment. The majority of recreational therapists in this category indicated all goals but increase independence in daily living skills, increase performance tolerance, and increase relaxation skills as very important to treatment. These results are presented in Table 12.

In the category in which neither occupational therapy nor recreational therapy is represented in the facility, very similar results were found for goal importance. The majority of occupational therapists in this category indicated all goals except increase leisure planning, increase relaxation skills, and increase independence in daily living skills as very important to treatment. The majority of recreational therapists in this category indicated all except increase independence in daily living skills, increase attention span, increase problem solving, and increase performance tolerance as very important to treatment. These results are presented in Table 13. 
Table 12

Comparison of Major Goals by Importance - Both Occupational Therapists ( $N$ = 39) and Recreational Therapists ( $N=18$ ) Represented on Staff

\begin{tabular}{|c|c|c|c|c|c|}
\hline \multirow[b]{2}{*}{ Goal } & \multicolumn{2}{|c|}{ OT } & \multicolumn{2}{|c|}{$\mathrm{RT}$} & \multirow[b]{2}{*}{$\%$ Overlap } \\
\hline & $\underline{n}$ & $\%$ & $\underline{n}$ & $\%$ & \\
\hline Increase motivation level & 23 & 59 & 11 & 61 & 2 \\
\hline Increase purposeful activity & 23 & 59 & 11 & 61 & 2 \\
\hline Increase attention span & 27 & 69 & 13 & 72 & 3 \\
\hline $\begin{array}{l}\text { Increase independence in daily } \\
\text { living skills }\end{array}$ & 12 & 31 & 5 & 28 & 3 \\
\hline Increase communication skills & 30 & 77 & 13 & 72 & 5 \\
\hline Increase self esteem & 28 & 72 & 14 & 78 & 6 \\
\hline Increase frustration tolerance & 25 & 64 & 10 & 56 & 8 \\
\hline Increase problem solving & 29 & 74 & 11 & 61 & 13 \\
\hline Increase socialization skills & 23 & 59 & 14 & 78 & 19 \\
\hline Increase relaxation skills & 9 & 23 & 9 & 50 & 27 \\
\hline Increase performance tolerance & 24 & 62 & 4 & 22 & 40 \\
\hline Increase leisure planning & 5 & 13 & 13 & 72 & 59 \\
\hline
\end{tabular}


Table 13

Comparison of Major Goals by Importance - Occupational Therapists $(N=33)$ or Recreational Therapists $(N=9)$ not Represented on Staff

\begin{tabular}{|c|c|c|c|c|c|}
\hline \multirow[b]{2}{*}{ Goal } & \multicolumn{2}{|c|}{ OT } & \multicolumn{2}{|c|}{ RT } & \multirow[b]{2}{*}{$\%$ Overlap } \\
\hline & $\underline{\mathrm{n}}$ & $\%$ & $\underline{n}$ & $\%$ & \\
\hline Increase motivation level & 18 & 55 & 5 & 56 & 1 \\
\hline Increase purposeful activity & 19 & 58 & 5 & 56 & 2 \\
\hline Increase communication skills & 23 & 70 & 6 & 67 & 3 \\
\hline Increase frustration tolerance & 18 & 55 & 6 & 67 & 12 \\
\hline Increase socialization skills & 21 & 64 & 8 & 89 & 25 \\
\hline Increase self esteem & 24 & 73 & 9 & 100 & 27 \\
\hline Increase performance tolerance & 21 & 64 & 3 & 33 & 31 \\
\hline Increase relaxation skills & 8 & 24 & 5 & 56 & 32 \\
\hline $\begin{array}{l}\text { Increase independence in daily } \\
\text { living skills }\end{array}$ & 15 & 45 & 1 & 11 & 34 \\
\hline Increase attention span & 22 & 67 & 3 & 33 & 34 \\
\hline Increase problem solving & 27 & 82 & 4 & 44 & 38 \\
\hline Increase leisure planning & 8 & 24 & 6 & 67 & 43 \\
\hline
\end{tabular}


Additional comparisons were performed to determine if there was any overlap in the "other" goals and modalities added by respondents in the "other" section of the questionnaire. Both occupational therapists and recreational therapists indicated the following "other" modalities used in treatment: music appreciation, current events, collage, pet therapy, exercise, and relaxation techniques.

Alternative goals were also listed which respondents felt were important to their treatment sessions. The following are those which both disciplines listed: improve physical fitness, increase awareness of self and others, increase self expression, increase creative expression, and increase tolerance of environment.

Question 1: What are the treatment modalities used by occupational therapists and recreational therapists in mental health settings?

The treatment modalities used most frequently by occupational therapists in mental health are as follows: cooking/meal planning, time managment, leisure planning, stress management training, woodwork, leatherwork, and social outings.

The treatment modalities used most frequently by recreational therapists in mental health are as follows: leisure planning, stress managment training, physical games/sports, tabletop games, and social outings.

Question 2: What are the major goals of therapy as indicated for occupational therapists and recreational therapists in mental health settings?

The major goals of therapy as indicated for occupational therapists in mental health are as follows: (1) increase problem solving, (2) increase communication skills, (3) increase self-esteem, (4) increase attention 
span/concentration, (5) increase performance tolerance, (6) increase socialization skills, (7) increase frustration tolerance, (8) increase purposeful activity, and (9) increase motivation level.

The major goals of therapy as indicated for recreational therapists in mental health are as follows: (1) increase self-esteem, (2) increase socialization skills, (3) increase communication skills, (4) increase leisure planning, (5) increase purposeful activity, (6) increase motivation level, (7) increase attention span/concentration, (8) increase frustration tolerance, (9) increase problem-solving skills, and (10) increase relaxation skills. 


\section{CHAPTER 4}

\section{DISCUSSION, IMPLICATIONS, AND RECOMMENDATIONS}

With such a broad philosophical base and such a wide range of activities included in the realm of occupational therapy, it is easy to understand the role overlap that occurs between occupational therapy and other disciplines. When the words "play" and "leisure" appear to be such fundamental parts of occupational therapy's philosophical base, it is especially easy to see the conflict that can occur with recreational therapists, for whom the main focus of treatment are play and leisure-type activities.

Modality Use by Occupational Therapists

Results indicate that, overall, the most often used modality by occupational therapists is stress management training. Other commonly used modalities include leatherwork, cooking/meal planning, woodwork, leisure planning, social outings, time management, and assertiveness training, with the majority of occupational therapists indicating that they usually use these modalities in practice. Of these modalities, social outings were not mentioned in the literature reviewed. It was noted in the data that crafts were not chosen as frequently by those occupational therapists working in community based or day treatment settings as by those working in hospital based settings. This supports the premise by Evans (1985) that type of setting guides the selection of treatment methods by practitioners.

The least often used modality by occupational therapists was silk 
screening, with $83 \%$ of these respondents indicating that they never use this modality in practice. Other uncommon modalities included printing, tie dying, basketry, and oil painting, with at least $50 \%$ of occupational therapists indicating that they never use these modalities in practice.

Modality Use by Recreational Therapists

The most often used modality by recreational therapists, overall, is leisure planning, with the majority of these respondents indicating that they usually use this modality in practice. Other commonly used modalities include stress management training, physical games/sports, tabletop games, and social outings, each with at least $50 \%$ of recreational therapists indicating "usually" for these modalities. Stress management, physical activity, and games were some of the techniques reported by Austin (1991). The least often used modality for this group is silk screening, with $89 \%$ of recreational therapists indicating that they never use this modality. Other uncommon modalities for this group include basketry, tie dying, and oil painting, with the majority of recreational therapists indicating that they never use these modalities in practice.

\section{Goal Importance for Occupational Therapists}

The most important goal for occupational therapists appeared to be increase problem solving, with $78 \%$ of these respondents rating this goal as very important. Nine of the twelve listed goals were rated as very important by at least $56 \%$ of these respondents. Increase leisure planning and increase relaxation skills were the only two goals which did not receive majority ratings of very important. It was noted that four of the occupational therapists indicated either all 5's (= not important) or a combination of 4's and 5's for their ratings in the goal section of the questionnaire, but no written explanations were given for 
these responses. Also, two of these respondents added their own goals to the "other" section and rated these goals with 5 's as well. One possible explanation for these responses is that the coding system for this section may have been misinterpreted to be the opposite of what it actually was.

Goal Importance for Recreational Therapists

The most important goal for recreational therapists appeared to be increase self esteem, with 23 of the 27 respondents rating this goal as very important. The majority of the listed goals were rated as very important by recreational therapists as well, with the exception of increase independence in daily living skills and increase performance tolerance. These results are in accordance with some of the goals reported by Austin (1991) as used by recreational therapists.

\section{Comparison of Modalities}

The results suggest that there is overlap between occupational therapists and recreational therapists in the majority of modalities listed on the questionnaire, although this overlap is more pronounced in some modalities than in others. Comparison of modality use by occupational therapists and recreational therapists was separated into two categories in order to determine if this had any impact on the results. The researcher assumed that in facilities in which both occupational therapy and recreational therapy were represented on staff, there would be less overlap in modalities and goals than there would be if one of the disciplines was not on staff. In other words, there would be more freedom of choice in the use of modalities if another discipline was not present. When the data were analyzed, however, different results were found. There appeared to be more overlap in the category in which both disciplines are 
represented in the facility, as indicated by more similar frequency responses for each of the listed modalities. One possible explanation for this result is that in facilities in which both disciplines are represented, there is more opportunity for co-treatment sessions. In these cases, in which occupational therapists and recreational therapists act as co-leaders for the same type of session, there would obviously be a greater amount of overlap.

There were no modalities that were completely exclusive to one discipline or the other, although there were a few in which there was a large difference in frequency of use. For example, recreational therapists appeared to use physical games/sports far more frequently than occupational therapists, regardless of whether or not both disciplines are on staff. Leisure planning is also used more frequently by recreational therapists than by occupational therapists. Results indicate that occupational therapists utilize the majority of crafts more frequently than recreational therapists in both categories. However, in the category in which both disciplines are represented on staff, recreational therapists appeared to use modalities such as cooking, grooming, shopping, and money management more frequently than occupational therapists. In the category in which occupational therapy or recreational therapy is not represented on staff, occupational therapists appeared to be the most frequent users of these modalities.

Comparison of Goal Importance

Goal importance was also compared according to the two categories described earlier. Overall, both occupational therapists and recreational therapists rated the majority of goals as "very important," regardless of category. The results suggest that goals concerning leisure planning and 
relaxation skills are not as important to occupational therapists as the others, since these were the only two goals which were not rated as "very important" by the majority in both categories. Results indicate that recreational therapists do not consider goals to increase performance tolerance and increase independence in daily living skills to be as high in importance as the other listed goals, as these were the only goals without majority ratings of "very important" by this group. Overall, the highest percentage of recreational therapists (85\%) rated increase self-esteem as very important, whereas the highest percentage of occupational therapists $(81 \%)$ rated increase problem-solving skills as very important.

\section{Conclusions}

The following tentative conclusions may be drawn from this study: 1. There is overlap between the modalities used by occupational therapists and those used by recreational therapists in the field of mental health, especially in facilities in which both disciplines are represented on staff.

2. Crafts such as silk screening, printing, tie dying, basketry, and oil painting appear to be phasing out of the repertoire of modalities used by occupational therapists.

3. The more traditional occupational therapy modalities, such as grooming/hygiene skills, cooking/meal planning, and leisure planning are now also being utilized by recreational therapists.

4. Leisure planning as a treatment modality is being used more frequently by recreational therapists than by occupational therapists. 
5. The most frequently used modalities by recreational therapists in mental health settings are: leisure planning, stress management training, physical games/sports, tabletop games, and social outings.

6. The most frequently used modalities by occupational therapists in mental health settings are: stress management training, leatherwork, woodwork, leisure planning, ceramics, tile mosaics, social outings, time management, and assertiveness training.

7. There is overlap in goal importance between occupational therapists and recreational therapists in mental health settings.

8. Goals to increase self-esteem, increase leisure planning, and increase relaxation skills are more important to recreational therapists than to occupational therapists.

9. Goals to increase problem-solving, increase independence in daily living skills, and increase performance tolerance are more important to occupational therapists than to recreational therapists.

10. There do not appear to be any modalities unique to either occupational therapy or recreational therapy since there were no complete exclusions in usage for one discipline or the other.

11. There do not appear to be any goals unique to either occupational therapy or recreational theralpy; however, there are goals that are more important to treatment planning for each discipline.

\section{Implications}

In the field of mental health, it may be important for occupational therapists to clarify a unique and distinct role on the multidisciplinary team From this study and from the literature, it has been shown that role overlap 
between occupational therapists and recreational therapists exists in mental health settings. Although results indicate that there are still more facilities with both occupational therapy and recreational therapy on staff, there is the definite possibility that occupational therapy positions may be gradually eliminated, especially if there are recreational therapists who can perform some of the same functions as occupational therapists at a lower salary.

Perhaps the profession of occupational therapy should explain its distinct and unique role in mental health settings in terms of its approach to treatment, rather than in terms of modalities. It may also be helpful for occupational therapists to share the distinction of their performance with other mental health professionals in terms of theory and frames of reference. Occupational therapists could further explain their performance in terms of the understanding that they possess of disability and how disability affects occupational performance.

\section{Recommendations}

As a result of this study a number of recommendations can be made for further research:

1. In a replication of this study, add a question to the questionnaire used in this study regarding whether or not co-treatment occurs between disciplines, and, if so, between which disciplines and in what types of groups or sessions.

2. In a replication of this study, limit the final sample population to therapists working in one type of setting with one type of population in order to see if more consistent or conclusive results are obtained. 
3. In a replication of this study, survey a national sample in order to increase validity and generalizability.

4. In a replication of this study, revise the goal section of the questionnaire to obtain more conclusive results. Several of the occupational therapists commented that they do not like to use the word "increase" for their goals. Instead, words such as "monitor" or "promote" are felt to be more appropriate. 5. In a replication of this study, include a question on the questionnaire used in this study regarding approach or frame of reference used in treatment. 


\section{REFERENCES}

Austin, D. R. (1991). Therapeutic Recreation: Processes and Techniques (2nd ed.). Champaign, IL: Sagamore Publishing, Inc.

Barris, R., Kielhofner, G., \& Watts, J. H. (1983). Psychosocial Occupational Therapy: Practice in a Pluralistic Arena. Laurel, MD: RAMSCO.

Biers, L., \& Murphy, J. F. (1970). A descriptive study of educational needs and career blockages. American Journal of Occupational Therapy, 24 . 196-200.

Bonder, B. R. (1987). Occupational therapy in mental health: Crisis or opportunity? American Journal of Occupational Therapy, 41(8), 495-498.

Caron, N. (1990). OT shortages in mental health: A student's perspective. OT Week, 4(32), p. 7.

Clark, P. N. (1979). Human development through occupation: Theoretical frameworks in contemporary occupational therapy practice, part 1. American Journal of Occupational Therapy, 33, 577-586

Cottrell, R. F. (1990). Perceived competence among occupational therapists in mental health. American Journal of Occupational Therapy. 44(2), 118123.

Dickerson, A., \& Kaplan, S. H. (1991). A comparison of craft use and academic preparation in craft modalities. American Journal of Occupational Therapy, 45(1), 11-17.

Evans, A. (1985). Roles and functions of occupational therapy in mental health. American Journal of Occupational Therapy, 39(12), 799-801.

Fidler, G. S. (1981). From crafts to competence. American Journal of Occupational Therapy, 35, 567-573. 
Florian, V., \& Sacks, D. (1985): Reasons for patient referral to occupational therapy units by health care professionals. Journal of Allied Health $\underline{38}$, $317-326$.

Hopkins, H. L. (1988). An Introduction to Occupational Therapy. In H. L. Hopkins \& H. D. Smith (Eds.), Willard and Spackman's Occupational Therapy (p. 4). Philadelphia: J.B. Lippincott Company.

Joe, B. (1990). Gail Fidler: untiring advocate for OTs in mental health. OT Week, $4(32)$, p. 6.

McGuire, T. G., \& Frisman, L. K. (1983). Reimbursement policy and costeffective mental health care. American Psychologist, 38, 935-947. Pedretti, L. \& Glogoski, C. (1988). Methods, Activities, and Skills Used in Occupational Therapy Practice. Unpublished study, San Jose State University, San Jose, CA.

Peters, M. E. (1984). Reimbursement for psychiatric occupational therapy services. American Journal of Occupational Therapy, 38(5), 307-312. Van Deusen, J. (1990). Can we delimit the discipline of occupational therapy? American Journal of Occupational Therapy, 44(2), p. 175. Wiemer, R. (1979). Traditional and Nontraditional Practice Arenas. Occupational Therapy: 2001, Rockville, MD: American Occupational Therapy Association. 
APPENDIX A

QUESTIONNAIRE 


\section{GENERAL INFORMATION}

My current position is:

Recreational Therapist

Occupational Therapist

Type of mental health setting I work in is:

hospital based

community based

day treatment

other (please specify)

Primary population I presently work with is: (check all that apply) children adolescents adults seniors other (please specify)

Other activity therapy disciplines I currently work with are: (please specify number of each)

Number: occupational therapists recreational therapists art therapists music therapists other (please specify) 


\section{MODALITIES}

Please indicate the frequency with which you use the following modalities in treatment by placing an $X$ under the appropriate category for each item.

1. Groominghygiene skills

2. Home/personal safety

3. Cooking/meal planning

4. Shopping

5. Time management

6. Money management

7. Leisure planning

8. Stress management training

9. Assertiveness training

10. Needlecrafts

11. Ceramics/pottery

12. Woodwork

13. Printing

14. Silk screening

15. Stenciling

16. Tie dying

17. Jewelry making

18. Copper tooling

19. Leatherwork

20. Decoupage

21. Paper crafts

22. Tile mosaics

23. Stained glass

24. Basketry

25. Water color

26. Oil painting

27. Tempera/acrylics

28. Finger painting

29. Physical games/sports

30. Tabletop games

31. Electronic equipment (VCR's,

Usually $(51-100 \%)$

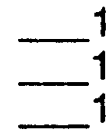

$-1$

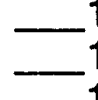

1
-1

$-1$

$-1$

$-1$

$-1$

$-1$

$-1$

$-1$

$-1$

$-1$

$-1$

1
-1
-1
-1
Sometimes Never (1-50\%)

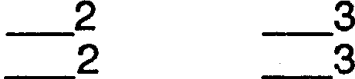

$-2 \quad 3$

$-2 \quad-3$

2
-2
-3

-2
-3

$-2 \quad 3$

$-2 \quad 3$

$-2 \quad-3$

2
-3

$-2 \quad 3$

$2 \quad 3$

$-2 \quad 3$

2

2

2

$-2$

2

2

2

2

2

2

2

2

2

2

2

$-2$
3
3
3
3
3
3
3
3
3
3
3
3
3
3
3
3

3

3

3

3

3

3

3

3

3

3

3

3

3

3 camcorders, computers, etc.) 
32. Social outingsfield trips

Usually
$(51-100 \%)$
1 $\stackrel{\begin{array}{c}\text { Sometimes } \\ (1-50 \%)\end{array}}{-2} \begin{array}{r}\frac{\text { Never }}{(0 \%)} \\ 3\end{array}$

33. Other(s) (please specify):

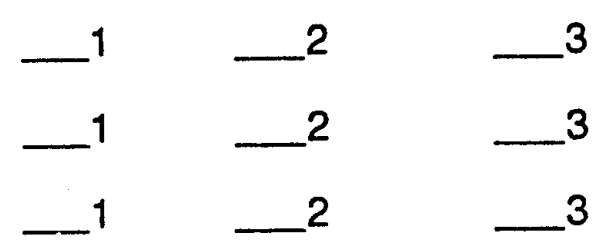

\section{GOALS OF THERAPY}

Please rank the following goals according to their importance in your therapy sessions: (circle one)

$$
1=\text { very important .....................................5 = not important }
$$

1. Increase attention span/concentration

$$
\begin{array}{lllll}
1 & 2 & 3 & 4 & 5
\end{array}
$$

2. Increase communication skills

$$
\begin{array}{lllll}
1 & 2 & 3 & 4 & 5
\end{array}
$$

3. Increase purposeful activity

$$
1 \quad 2 \quad 3 \quad 4 \quad 5
$$

4. Increase self esteem

$$
\begin{array}{lllll}
1 & 2 & 3 & 4 & 5
\end{array}
$$

5. Increase problem solving skills

$$
\begin{array}{lllll}
1 & 2 & 3 & 4 & 5
\end{array}
$$

6. Increase socialization skills

$$
\begin{array}{lllll}
1 & 2 & 3 & 4 & 5
\end{array}
$$

7. Increase leisure planning

$$
\begin{array}{lllll}
1 & 2 & 3 & 4 & 5
\end{array}
$$

8. Increase frustration tolerance

$\begin{array}{lllll}1 & 2 & 3 & 4 & 5\end{array}$

9. Increase motivation level

$$
\begin{array}{lllll}
1 & 2 & 3 & 4 & 5
\end{array}
$$


10. Increase relaxation skills

$$
\begin{array}{lllll}
1 & 2 & 3 & 4 & 5
\end{array}
$$

11. Increase independence in daily living skills (ie: personal care, cooking, and cleaning)

$$
\begin{array}{lllll}
1 & 2 & 3 & 4 & 5
\end{array}
$$

12. Increase performance tolerance (ability to complete a task)

$$
\begin{array}{lllll}
1 & 2 & 3 & 4 & 5
\end{array}
$$

13. Other(s):

$\begin{array}{lllll}1 & 2 & 3 & 4 & 5\end{array}$

$\begin{array}{lllll}1 & 2 & 3 & 4 & 5\end{array}$


APPENDIX B

COVER LETTER 
Dear Occupational Therapist:

Your help in conducting a study regarding the roles and functions of recreational therapists and occupational therapists working in mental health is being sought to increase our understanding of the similarities and differences between these two disciplines, and hopefully pinpoint areas in which each group is unique and distinct from the other in their approaches to treatment.

Attached is a questionnaire listing several treatment modalities and goals used by occupational therapists and/or recreational therapists. Your time and effort in completing this questionnaire will be greatly appreciated. You should be clear that your participation in this study is voluntary and you may refuse to participate without prejudice to your relations with SJSU. All answers will be regarded confidentially. If you have any questions or complaints about research subject's rights, contact Serena Stanford, Ph.D. (Associate Academic Vice President for Graduate Studies \& Research) at (408) 924-2480.

Enclosed please find a self-addressed stamped envelope in which to return your completed questionnaire by December 20, 1991. If you have any questions about this study, I would be happy to talk with you. I can be reached at (408) 248-8050. Thank you very much for your participation.

Sincerely,

Elaine Saghafian

Graduate Student 
Dear Recreational Therapist:

Your help in conducting a study regarding the roles and functions of recreational and occupational therapists working in mental health is being sought to increase our understanding of the similarities and differences between these two disciplines, and hopefully pinpoint areas in which each group is unique and distinct from the other in their approaches to treatment.

Attached is a questionnaire listing several treatment modalities and goals used by occupational therapists and/or recreational therapists. Your time and effort in completing this questionnaire will be greatly appreciated. You should be clear that your participation in this study is voluntary and you may refuse to participate without prejudice to your relations with SJSU. All answers will be regarded confidentially. If you have any questions or complaints about research subject's rights, contact Serena Stanford, Ph.D. (Associate Academic Vice President for Graduate Studies \& Research) at (408) 924-2480.

Enclosed please find a self-addressed stamped envelope in which to return your completed questionnaire by December 20, 1991. If you have any questions about this study, I would be happy to talk with you. I can be reached at (408) 248-8050. Thank you very much for your participation.

Sincerely,

Elaine Saghafian

Graduate Student 